\title{
Subjective intensity of a familiar liquid substance--coffee'
}

LEROY A. STONE and RICHARD E. HARDER, The University of North Dakota. Grand Forks, N.D. 58201

Judges judged a sequence of coffee stimulus presentations with respect to strength or intensity. The psychophysical methods of magnitude estimation and of single stimuli were used. Power functions appropriately described the individual and group psychophysical relationships. The computed PSE appeared to correspond closely to suggestions made by the coffee stimulus manufacturer. A clustering of stimuli, based on subjective intensity values, was undertaken.

Over three decades ago, Bujas (1937), when matching salty with sweet, regarding magnitude of sensation, found that ratio units of taste were seemingly more valid than jnd units. Almost all psychophysical investigations which have employed the direct ratio scale methods in the area of gustation study have used stimuli which could be easily associated with specific primary taste qualities, i.e., sour, salty, bitter, and sweet (a very brief review of some of these studies may be found in Ekman \& A kesson, 1965). It is interesting to note that in the opinions of Bruvold \& Gaffey (1965, p. 369) "only a small amount of research has been performed that employs magnitude estimation to investigate subjective intensity for the modality of taste." Conceivably, judges (Js), adult and mentally competent humans normally used in gustatory psychophysics, have had some (or perhaps a great deal of) experience with stimuli which seem to excite only specific taste qualities. However, it is more likely that most gustatory experiences are with substances which excite a combination of taste qualities.

The purpose of the present investigation was to study the psychophysical relation between subjective intensity and gustatory stimulus substances (coffee solutions) which were known to be highly familiar to the Js. This relation was studied using two quite different psychophysical methodologies: direct estimation and the method of single stimuli (cf. Wever \& Zener, 1928). The direct estimation technique employed was magnitude estimation (no assigned modulus; $\mathrm{cf}$. Stevens, 1957) of subjective strength. The method of single stimuli was used to elicit dichotomous impressions of "strong-weak."

The six Js were male graduate students in psychology (ages 22 to 27 years) who regarded themselves as moderate to heavy coffee consumers. The stimuli were seven coffee solutions of differing concentration and were made using powdered or "instant" coffee (Butternut brand). The different solutions were based on differing amounts of powdered coffee in a standard amount $(158.33 \mathrm{cc})$ of the solvent, distilled water. The seven differing amounts of powdered coffee were: $0.93 \mathrm{cc}$ (corresponding to $.25 \mathrm{tsp}), 1.86 \mathrm{cc}(.50 \mathrm{tsp}), 2.78 \mathrm{cc}$ (.75 tsp), $3.71 \mathrm{cc}$ (1 tsp), $5.56 \mathrm{cc}(1.50 \mathrm{tsp}), 7.42 \mathrm{cc}$ ( $2 \mathrm{tsp})$, and $11.13 \mathrm{cc}(3 \mathrm{tsp})$. The $158.33 \mathrm{cc}$ or 5.37 fluid ounces of distilled water corresponds to the amount contained in what is termed as a "coffee cup."

Several hours before each $J$ arrived the Es prepared the seven stimulus solutions. The solutions were then left to assume the temperature of the laboratory, which was kept very near to $70 \mathrm{deg} F$ ). A sink was used with the tap open during the stimulus presentations and during the subsequent expectorations. Each stimulus presentation consisted of $3.71 \mathrm{cc}(1 \mathrm{tsp})$ of concentrate solution. With each presenta- tion, the $J$ held it in his mouth until he was able to establish a judgment. After each expectoration, the $J$ rinsed his mouth with the required amount of distilled water (also kept at $70 \mathrm{deg}$ F). After rinsing, a 1.5-min rest interval was used before the next stimulus presentation. Each blindfolded J was presented with 20 randomly determined series of the seven stimuli. Each J was tested on two sets of series. once with the instructions for making magnitude estimations regarding strength of stimulus and once with instructions for making the dichotomous "strong-weak" judgments. For half of the Js, the magnitude estimation task was first (the first 10 presented series); for the remaining half, the method of single stimuli was used during the first series.

The six subjective magnitude estimation scales (for individual Js) of coffee strength or intensity were plotted against the stimulus variable, amount of powdered coffee per $158.33 \mathrm{cc}$ of solvent, in $\log$-log coordinates. Geometric means were used as the scale statistic. Straight lines were found to offer reasonably good approximations to the data trends, i.e., power functions appropriately describe the psychophysical relation for all Js. The six slopes (power function exponents) were, in order: $.50, .67, .71, .89,1.00$, and 1.09 . The group exponent was .75 (see Fig. 1). This magnitude scale correlated highly with the physical measure $(r=.96, \mathrm{df}=5, \mathrm{p}<.01)$.

The absolute judgment scale values were calculated from the portions of "strong" judgments and for which corresponding normal deviate $\mathrm{Zs}$ were assigned. The range of this $\mathrm{Z}$ scale was 0.00 to 4.38 . The $r$ between the absolute judgment scale and the magnitude scale was $.98(\mathrm{df}=5, \mathrm{p}<.01)$ and between the absolute judgment scale and the physical measure the $r$ was .93 ( $\mathrm{df}=5, \mathrm{p}<.01$ ). Utilizing the absolute judgments, a Weber fraction was computed (using the $\mathrm{SD}$ as a measure of dispersion) and found to be equivalent to .55. This would suggest that, with the Js employed, a coffee solution must contain approximately half again as much powdered coffee in order to be reliably discriminated from a weaker coffee solution. The $k$ value in fitting Fechner's law to this data was seen to be 7.1 I with this value, the fit of the psychophysical relation was

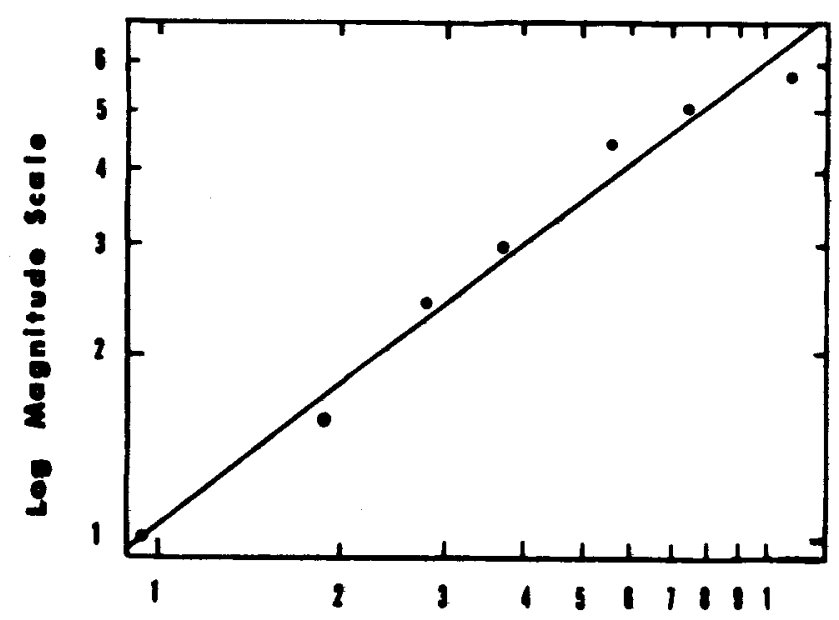

Low Coffee strength (ee $\times 10)$

Fig. 1. The relation between $\log$ magnitude scale and $\log$ coffee strength (cc $\times 10$ ). 
excellent $\left(x^{-}=.002, \mathrm{df}=1, \mathrm{p}>.95\right)$ based only on the three stimulus vaiues above the PSE associated with the dichotomy of "strong-weak."]. The calculated PSE value was equivalent to $3.78 \mathrm{cc}$ ( $1.02 \mathrm{tsp})$ of powdered coffee. The standard error for this PSE was approximately $19 \mathrm{cc}$.

A rather new technique, which is fully described in detail by Stone (1968), was employed which allowed the grouping of stimuli into similarity clusters. This stimulus clustering is based only on information derived from the subjective magnitude estimation scale values. The stimulus clustering procedure is based on the similarity measure paradigm first suggested by Eisler \& Ekman (1959) combined with correlational cluster analysis thinking. Stimuli are clustered so that each cluster represents a group of stimuli which possess more betweenstimuli similarity than they have with stimuli outside of the cluster. Following the procedure outlined by this clustering model three stimulus clusters emerged from the present magnitude estimation scale information: Cluster 1 (0.93 and $1.86 \mathrm{cc})$, Cluster $2(2.78$ and $3.71 \mathrm{cc})$, and Cluster 3 (5.56, 7.42 , and $11.13 \mathrm{cc}$ ).

\section{DISCUSSION}

A power function appears to yield a rather satisfactory fit with respect to the group data for coffee strength. Although they are not presented here, it was evident from graphic representations that with individual Js, power functions also provided reasonably good fits. The individual exponents appeared to vary widely; this is quite consistent with previous gustatory investigations involving direct estimations (e.g., Ekman \& $\AA$ kesson, 1965). With the group exponent having a value less than unity (negatively accelerated trend), the zero stimulation value would, by extrapolation, correspond to approximately slightly less than $.20 \mathrm{cc}$ (about .05 of a tsp) of powdered coffee in the standard amount of solvent (158.33 or one coffee cup).

The data obtained under the classical psychophysical paradigm would suggest that preference (PSE with respect to "strong-weak," or the limen regarding "strong") corresponds rather closely to the amount suggested by the coffee manufacturers. The amount suggested by the manufacturers is 1 tsp whereas the obtained PSE (or "strong" limen) was $3.78 \mathrm{cc}$ (or $1.02 \mathrm{tsp}$ ). This PSE was based on a least-squares solution using Muller-Urban weights (Guilford, 1954).

It would appear (Fig. 1) that a doubling of a stimulus intensity results in a less than doubling of subjective intensity. In order to achieve a doubling of subjective intensity, the physical intensity must be increased approximately four times.

The results of the unidimensional-scale stimulus-clustering operation revealed three general clusters which seemed to make sense psychologically, the weak-stimulus cluster being the .25- and .50-tsp coffee stimuli, the medium strength stimulus cluster corresponding to .75- and 1-tep stimuli, and the third cluster being composed of the 1.50, 2-, and 3-tsp stimuli.

It would be most intriguing to replicate the study, however, instead of using Js who were very familiar with the stimulus substance, to use naive Js instead (perhaps based on religious convictions). The possible effect of previous taste experience might be conjectured by comparing individual and group exponents to those presently obtained.

\section{REFERENCES}

BRUVOLD, W. H., \& GAFFEY, W. R. Subjective intensity of mineral taste in water. Journal of Experimental Pyycholowy, 1965, 69, 369-374.

BUJAS, Z. La measure de la sensibilite differentielle dana la domaine gustatif. Acta Institutum Psychologica, University of Zagreb, 1937, 2, 1-18. Cited by C. Pfaffmann, Taste and amell. In S. S. Stevens (Ed.) Handbook of experimental psychology. New York: Wiley, 1951.

EISLER, H., \& EKMAN, G. A mechanism of aubjective similarity. Acta Psychologica, 1959, 16, 1-10.

EKMAN, G., AKESSON, C. Saltneas, sweetness, and preference: A study of quantitative relations in individual subjects. Scandinavian Journal of Psychology, 1965, 6, 241-253.

GUILFORD, J. P. Psychametric methods. New York: McGraw-Hill, 1954.

STEVENS, S. S. On the psychophysical law. Psychological Review, 1957, $64,153-181$.

STONE, L. A. Stimulus clusters from subjective ratio scale information: Two preliminary investigations. Reports of the Psychological Laboratory, University of Stockholm, 1968, No. 245. Also read at Psychonomic Society meetins, St. Louis, Mo., October, 1968.

WEVER, E. G., \& ZENER, K. E. The method of absolute judgment in psychophysics. Psychological Review, 1928, 35, 466-493. NOTES

1. This research was supported by a Public Health Service Fellowship (1-F3-MH-12,317-01) from the National Institute of Mental Health and by a grant from the University Committee on Rexearch, The University of North Dakota, both to the first author.

2. In the Webster's new international dictionary of the English language. IW. T. Harris and F. S. Allen (Eds.), Sprinefield, Mass.: Merriam Company, 1928l a teacupful is estimated as about four fluid ounces (p. 2119) and a coffee cup is described as one-third larger than a teacup (p. 431), hence a coffee cup can be regarded as holding 5.33 fluid ounces (or $158.33 \mathrm{cc}$ ). 